\title{
Divergent Approaches to Access: How Selective College Admissions Offices Recruit Lower- Income, First-Generation, and Working-Class Students
}

\author{
Hannah Gunther, Colgate University \\ Janel Benson, Colgate University
}

\begin{abstract}
In recent years, selective colleges and universities have made diversifying their student bodies a top priority, yet the class diversity on these campuses has barely shifted. While most research on class disparities in college admissions focuses on student explanations, this study seeks to understand how campus admissions approaches to recruitment may also contribute to why so few lower-income, firstgeneration, and/or working-class students (LIFGWC students) attend selective colleges. To address this question, we conducted interviews with seven admissions officers from selective campuses with both relatively strong and weak records of LIFGWC students recruitment. Institutions with stronger records of recruiting LIFGWC students actively sought out new initiatives to make their college more accessible for LIFGWC students, and these actions were motivated by a shared focus on improving larger societal inequality. Although campuses with weaker records also expanded their recruitment strategies, their efforts were often piecemeal and motivated by competition for students and institutional rankings rather than a larger mission to improve diversity and equity. These findings suggest that institutional missions and philosophies are central to increasing access.
\end{abstract}

\section{Keywords}

First-generation student, low-income students, undergraduate admission, undermatching, diversity

\section{Introduction}

First-generation, low-income, and/or working-class students (hereafter LIFGWC students) reap a range of benefits from attending selective colleges, including strong academic and financial support, high graduation rates, and connections into professional careers (Lee, 2013; Benson \& Lee, 2020). Selective colleges can also have a substantial impact on social mobility; LIFGWC students who attend selective colleges end up earning about as much as students from wealthier backgrounds (Aisch et al., 2017). Despite these benefits, scholars question whether selective colleges genuinely aim to advance social mobility (Hurst, 2019). For example, the representation of LIFGWC students at selective colleges generally has not changed much in the last four decades, even as access for other underrepresented groups has increased (Rouse \& Barrow, 2006; Lee, 2013; Hurst 2019).

Despite having similar college aspirations, LIFGWC students are less likely to attend selective colleges and universities compared to students whose parents are college-educated (Redford \& Hoyer, 2017). High- 
achieving LIFGWC students consistently undermatch in the college selection process, attending campuses of lower selectivity than they are qualified to attend (Bowen et al., 2009; Roderick et al., 2011; Smith et al., 2013). This is largely because so few high-achieving, LIFGWC students apply to selective colleges (Hoxby \& Avery, 2013). In addition to missing out on the financial and academic benefits of attending selective campuses, LIFGWC students who undermatch take longer, on average, to graduate, have lower graduation rates, and less positive employment outcomes compared to students who attend institutions that align with their abilities, further increasing social class inequality (Bowen et al., 2009; Ovink et al., 2017; Shamsuddin, 2016).

To understand why so few high-achieving LIFGWC students choose to apply to selective colleges and universities, scholars and policymakers tend to focus on deficits in students' backgrounds. For example, LIFGWC students tend to have less access to college knowledge, application support, and related preparation resources compared to their more advantaged peers, leading to more constrained college search patterns (Holland, 2014; Holland, 2020; Grodsky \& Riegle-Crumb, 2010; Alon, 2009; Engberg et al., 2012). What is less understood, however, is how selective colleges and universities contribute to this undermatching process through their recruitment approaches. Recent studies show that LIFGWC students are especially responsive to marketing and recruitment tactics (Holland, 2019; Dynarski et al., 2018), suggesting that the ways colleges and universities recruit applicants is a key part of the undermatching puzzle.

In this study, we build on literature on LIFGWC students undermatching and college selection to examine the practices selective colleges use to approach the recruitment of LIFGWC students and whether these practices are linked with the successful recruitment of LIFGWC students. To answer these questions, we interviewed seven college admissions officers (AOs), the gatekeepers of college access, from selective campuses with both relatively strong and weak records of LIFGWC students recruitment, as indicated by the percentage of Pell Grant-eligible students on campus. In doing so, we aim to understand if differences in recruitment approaches explain, at least in part, why some campuses are better than others at recruiting students from this underrepresented demographic.

\section{Literature: LIFGWC students College Access and Admissions}

In order to understand admissions recruitment processes, it is important to examine both the decisions institutions make as well as their rationale or justification for these approaches. To do so, we draw upon a cultural toolkit approach (Swidler, 1986) to examine both the recruitment strategies and motivating philosophies used by selective college admissions offices. Recruitment strategies are the concrete practices admissions personnel use, such as offering fee waivers, to remove barriers and attract LIFGWC students. On the other hand, recruitment philosophies or logics are the more abstract component of the decision-making process (Harding, 2007; Small, 2004). This is the lens through which admissions personnel view potential applicants and admissions priorities. These frameworks are critical because they often guide institutional priorities, investments, and decisions.

Previous research on recruitment philosophies tends to focus largely on racial diversity and treat all selective colleges as a singular entity (Stulberg \& Chen, 2013; Glasener et al., 2019; Ahmed, 2012). Very few studies examine campus motivations to increase class diversity. One exception is Rubin's (2011) historical analysis of admissions practices at Amherst College, a selective college with relative success in enrolling high numbers of low-income students, which connects colleges' motivations surrounding 
diversity to their recruitment of low-income students. Rubin (2011) finds it is not one specific policy or combination of policies that worked to improve class diversity for Amherst, but a historical commitment from administrators to socioeconomic and racial diversity that made the difference. This work suggests that institutional motivating philosophies are critical to understanding how campuses approach improving access for underrepresented students.

Motivations do not always come from deep institutional commitments to diversity but rather from interests to improve rankings and prestige. Selective colleges often recruit underrepresented students because diversity is expected at a selective institution and makes the college more prestigious (Golden, 2006; Cashin, 2014; Okechukwu, 2019). Ultimately, however, rankings are not determined by how truly diverse or accessible a college is, but rather, schools chase rankings measured by 'pre-existing privilege' (i.e. acceptance rates and average SAT scores) (Hurst, 2019, p. 79). Thus, scholars argue that higher education institutions engage in performative commitments to diversity, rather than genuine commitments (Ahmed, 2012; Okechukwu, 2019). Ahmed (2012) notes, 'diversity work becomes about generating the 'right image' and correcting the wrong one' (34). Cashin (2014) refers to this concept as 'optical diversity,' arguing colleges accept affluent students of color because it makes them appear diverse, but do not work to foster real inclusion (41). In this way, scholars argue that diversity approaches are more of a marketing tactic than efforts to alleviate forms of inequality by expanding access (Stevens, 2007; Stulberg \& Chen, 2013; Ahmed, 2012; Okechukwu, 2019).

Other work suggests that campuses interested in expanding class diversity also face conflicting goals. Colleges may want to increase socioeconomic diversity and expand financial aid to do so, but also need to recruit full pay students to meet their bottom-line (Cashin, 2014; Lee, 2016). In addition, it is challenging to shift long-held institutional preferences, values, and culture, often referred to as institutional habitus (Reay et al., 2001). Since the beginning of higher education in the United States, colleges have predominantly served affluent, white students, resulting in admissions practices and commitments that largely benefit this group (Stevens, 2007; Golden, 2006; Killgore, 2009; Lee, 2016). Although campuses may aim to expand class diversity, their approaches may be limited by financial resources, long-standing stakeholders, and deeply entrenched practices.

Unlike motivating philosophies, there is robust literature on the types of policies and practices campuses have successfully implemented to increase their LIFGWC students population. First, selective colleges have begun to identify new ways to attract LIFGWC students who often have less familiarity with these types of campuses and/or are intimidated by costs (McDonough, 1997; Holland, 2014; Lee, 2013). One strategy is to visit students within their high schools and communities. Although many selective colleges tend to target predominantly private and affluent public high schools with their visits (Salazar et al., 2021), some campuses have expanded their efforts to intentionally include schools in predominantly lowerincome and/or racial minority communities (Okechukwu, 2019) and have begun building new partnerships with community-based organizations (CBOs) within these communities (Simmons \& Hewitt, 2018; Hooker \& Brand, 2009; Coles, 2012; Holland, 2019). In addition, many selective campuses now host flyin programs, which provide interested LIFGWC students a fully-funded opportunity to visit campus and meet with current faculty and students. Research shows that the campus visit is critical to recruitment (Dearden et al., 2017), yet many LIFGWC students do not have the resources to visit campuses, especially those far from home (Holland, 2014). Fly-in programs are especially valuable for improving college access for LIFGWC students because they provide an opportunity to learn about a specific campus and college life in general. 
Second, some selective campuses have implemented a more holistic application review process that acknowledges some of the barriers faced by LIFGWC students. In recent years, many selective campuses have made standardized tests optional based on evidence showing that bias within college admissions tests artificially deflated LIFGWC students' scores (Simmons \& Hewitt, 2018; Alon, 2009; Holzman et al., 2020; Dache-Gerbino, 2018; Guinier, 2015). In addition, there has been some recognition of the class bias built into the traditional application markers of character and well-roundedness (Stevens, 2007; Cheadle, 2008; Hamilton et al., 2018). For example, some AOs take a broader view on high school engagement by considering responsibilities often unique to LIFGWC students, such as employment, on par with traditional leadership and extracurricular involvement. Finally, many selective campuses offer application and test-score fee waivers to reduce the financial barriers to the application process, and offer significant financial aid packages that reduce the overall cost of attendance.

Although many selective campuses are investing in efforts to increase the recruitment of LIFGWC students, we argue that the impact of these efforts depends on the motivating philosophies behind them. We find that motivating philosophies for increasing class diversity are linked to ways strategies are implemented and ultimately, their success. By comparing the recruitment approaches used by selective colleges with strong and weak records of enrolling LIFGWC students, this study builds upon Rubin's (2011) work by showing how commitments to equity are the key component to improving access for LIFGWC students.

\section{Data and Methods}

To examine how selective colleges recruit LIFGWC students and whether these strategies are linked with successful records of LIFGWC students attendance, we interviewed selective college ${ }^{1}$ admissions officers (AOs) from campuses with both relatively strong and weak records of LIFGWC students enrollment. Specifically, we used data on the percentage of Pell Grant recipients from 'Mobility Report Cards ${ }^{26}$ to select eight admissions officers from low socioeconomic diversity colleges (LDC) and eight from high socioeconomic diversity colleges (HDC) to be interviewed for this study. We define campus socioeconomic diversity based on the percentage of enrolled students receiving Pell Grants. Pell Grant eligibility, a metric also used by U.S News and World Report to measure campus economic diversity, includes students whose total family income is $\$ 50,000$ a year or less, which is roughly equivalent to $200 \%$ of the 2021 Federal Poverty Line for a family of four. HDCs are those with greater than $20 \%$ of enrolled students receiving Pell Grants, while LDCs have less than $14 \%$ of enrolled students receiving Pell Grants.

Table 1 includes the information about the socioeconomic diversity of each campus in the sample. All institution names are pseudonyms. Four AOs from LDC campuses and three from HDC campuses agreed to participate. To maintain consistency across the interview sample, all AOs in the sample are responsible

\footnotetext{
${ }^{1}$ This study defines selective colleges as schools that admit less than 30 percent of applicants, and all colleges sampled rank as level 1 or 'most competitive' on Barron's Profiles of American Colleges list.

2 To determine which colleges to select, we used the dataset from the study 'Mobility Report Cards: The Role of Colleges in Intergenerational Mobility by Opportunity Insights' (Chetty et al. 2017). This dataset was used to provide background information on the socioeconomic demographics of the school, as many schools do not have this information readily available on their websites.
} 
for the same geographic region. ${ }^{3}$ The AOs in this study come from predominantly small to medium-sized campuses, with the exception of Robertson University, which is a larger university. All sample campuses are private, and five of the seven are liberal arts colleges. It is important to note that all three of the HDCs are need-blind (meaning they do not consider an applicant's ability to pay tuition in their admissions decision) and meet $100 \%$ of demonstrated financial need. The four LDC campuses are not need-blind (although one recently announced they will eventually be implementing need-blind into their admissions practice), but they do meet $100 \%$ of students' demonstrated financial need.

\begin{tabular}{|c|c|c|c|c|c|}
\hline \multicolumn{6}{|c|}{ Sample of Selective Colleges and Universities } \\
\hline \multirow[t]{2}{*}{ College } & Pell Grant Recipients & Students from Bottom $60 \%$ & Students from the Top $1 \%$ & Total Undergraduate Enrollment & Domestic Students of Color \\
\hline & $\%$ & $\%$ & $\%$ & $n$ & $\%$ \\
\hline \multicolumn{6}{|c|}{ High SES Diversity (HD) } \\
\hline Patterson College & 24 & 26 & 9 & 2,800 & 41 \\
\hline Robertson University & 22 & 22 & 14 & 19,000 & 37 \\
\hline Sage College & 24 & 24 & 21 & 1,800 & 45 \\
\hline \multicolumn{6}{|c|}{ Low SES Diversity (LD) } \\
\hline Brooks College & 12 & 14 & 23 & 2,800 & 22 \\
\hline Chase College & 10 & 12 & 20 & 1,700 & 18 \\
\hline Tucker University & 10 & 6 & 22 & 7,500 & 39 \\
\hline Jamestown College & 9 & 8 & 19 & 1,800 & 15 \\
\hline
\end{tabular}

Source: Mobility Report Cards: The Role of Colleges in Intergenerational Mobility, by R. Chetty, J. Friedman., E. Saez, N. Turner, \& D. Yagan, December 2017, Opportunity Insights

(https://opportunityinsights.org/paper/mobilityreportcards/).

Study participants were recruited through an email that explained we were conducting a study on admissions practices, but did not specify the focus was on LIFGWC students. The intention was to see if LIFGWC students would come up in conversation without the interviewer asking about them, as this might give insight into the college's institutional logic and how LIFGWC students fit into the admissions office's work. The interviews were conducted over the phone or in person, and they lasted approximately 60 minutes. AOs were asked a range of questions about the admissions process. The interview started with broad questions about campus culture, the ideal applicant, and their recruiting strategies, and then moved to more specific questions about the recruitment of LIFGWC students. The interviews were transcribed and then coded using MaxQDA. We started by coding deductively for recruitment and enrollment strategies, and then used an inductive approach as we began to notice the HDCs and LDCs described different philosophies guiding their practices.

\section{Results}

\section{Motivating Philosophies}

The LDCs and HDCs in this study differed in their motivating philosophies, which in turn influenced the way campuses recruited and enrolled LIFGWC students. LDC admission officers (AOs) aimed to expand student diversity as a way to improve their specific campus. This was clear in AOs' explanations of the role of diversity in the recruitment process. Further, when LDC AOs spoke about campus diversity, they

\footnotetext{
3 Admissions' websites include information about which counselors cover each geographic region, such as New England, Metro New York, Southeast, etc.
} 
often used the term diversity more broadly, refraining from speaking about class diversity unless specifically asked. For example, when the Brooks University (LDC) AO describes campus diversity to prospective students, they told us:

I talk about how [diversity] sort of plays out in the classroom space, and the community...You're going to be in the classroom and the person sitting next to you is just going to blow you away because of where they're coming from, and who they are, and their perspective...So in terms of demographics and admission, we certainly talk about the profiles and the statistics in the fact sheet, but then we talk about how I think that plays out in terms of students' experiences here.

LDC AOs also linked diversity efforts to national rankings and recognition. For example, the Tucker University (LDC) AO explains,

We often start with questions about diversity really in the application process... Of course, we are looking at making sure that populations and demographics are represented on campus. Especially underrepresented demographics in the college arena. But also in making that transition to a more nationally recognized university.

The AO notes that as the school developed from a regional to a nationally ranked university over the last thirty years, increasing diversity has been a key piece of this strategy. Other LDC AOs in the sample echoed these sentiments, framing the recruitment of LIFGWC students as a way to become more competitive in the higher education marketplace.

In contrast, AOs at HDCs framed increasing campus class diversity as part of a larger goal of improving equity within broader society. For example, when asked about their recruitment approach, the AO at Robertson University (HDC) explained, 'I think we've always understood that college admission and higher education, in general is, on the whole, an effort to improve socioeconomic mobility, and that means bringing families up the socioeconomic ladder.' Additionally, rather than simply enrolling the most accessible LIFGWC students who will boost diversity statistics, the HDCs strive to expand their reach. When asked about the number of LIFGWC students applying to Sage College (HDC), the AO noted that not only do they have a lot of low-income students at their school, they are 'on the forefront' and 'pioneering' in regards to making college more accessible for LIFGWC students. They added that all of the initiatives for LIFGWC students, including meeting $100 \%$ of demonstrated financial need, applies to international, DACA, and undocumented students, noting they consider this 'one of the reasons [Sage] is one of the most accessible places of higher education.'

The HDCs were intentional about using admissions practices that benefitted LIFGWC students, even when they did not serve the campus bottom-line. The HDC AOs were conscious of admissions practices that may benefit the college, but disadvantage LIFGWC students. For example, the Robertson University (HDC) AO describes how some colleges 'certainly aren't acting in the best interest of students, [due to] the proliferation of early decision programs, this race to reduce the number of admission offers, and net revenue becomes the focus, and that is obviously not a low-income students oriented kind of paradigm.' Further, the HDC AOs often spoke about advocating for LIFGWC students. The Robertson University (HDC) admission officer states, 
We have to continue to make that case to the public at large that considering race, for example, and low-income status, for example, can be valid, educationally beneficial reasons to decide to admit students over others...I am afraid that we will go backward in this battle for equality.

The AO's emphasis on how they can more broadly serve LIFGWC students demonstrates a diversity philosophy that prioritizes benefiting the greater good over the college itself.

Ultimately, the difference in philosophies between the two groups of colleges seemed to play out in their strategies for recruiting and enrolling LIFGWC students. The HDCs are passionate about increasing socioeconomic mobility; thus, they seek out ways to improve the college process for LIFGWC students. On the other hand, the LDCs work to recruit and admit LIFGWC students, but are less aware of the ways these students are disadvantaged in the process. The lack of emphasis on class diversity by LDCs raises the question of whether LDCs engage in more performative strategies for increasing diversity, such as enrolling more affluent students of color. We divided the recruitment and enrollment strategies into two categories: broadening recruitment and reducing application barriers. We describe the differences in the approach to each strategy between the HDCs and LDCs.

\section{LIFGWC Recruitment Strategies}

While all campuses described using three best practice recruitment strategies to enroll LIFGWC studentshigh school recruitment visits, fly-in programs, and partnering with community-based organizations (CBOs)-HDCs and LDCs differed in their implementation of these practices, reflecting their distinct motivating philosophies. Moreover, HDCs were strategic in their efforts to diversify admissions staff as another way to build connections with under-served student populations, like LIFGWC students.

When selecting high schools for recruitment events, HDCs were intentional about selecting visit locations that maximize socioeconomic diversity, while LDC campuses tended to favor high schools where they had already established strong relationships. Robertson University (HDC) actively chose high schools with high percentages of low-income students to draw a diverse applicant pool. Both Sage (HDC) and Patterson (HDC) aimed to balance visits to private schools and low-income public schools to ensure they reach LIFGWC students. In contrast, the LDCs gave little consideration to diversity when selecting schools to visit. Tucker University (LDC) generally visited high schools where they previously have drawn the most applicants from: 'We actually go to schools, oftentimes our bread and butter schools, the ones that know us well, the ones that have lots of students who have applied in the past, and where we have relationships with the counselors.' By labeling these 'bread and butter' schools, the AO suggests the typical Tucker (LDC) student comes from a school where many students are applying to selective colleges, presumably affluent public or private schools. Likewise, when asked about how LIFGWC students find out about Chase College (LDC), the admission officer initially did not think that there was a difference in the way LIFGWC students found out about the college:

I'm not certain that [LIFGWC students] find out in ways that are different from... Well okay, I guess I see what you mean there, because the boarding schools that I visited, Chase's name comes up a lot more than at a high school...okay yeah...now that I talked about it out loud I'm like okay yeah, that makes sense. I'm not positive how they find out about it... 
While all AOs had trouble providing a single pathway for LIFGWC students, the fact that this AO had not considered LIFGWC students suggests that LDCs are less committed to expanding access and tend to stick with strategies that attract a typical white, affluent applicant.

Similarly, HDCs were more intentional than LDCs in expanding LIFGWC students recruitment through developing partnerships with community-based organizations (CBOs). For HDCs, this process was integrated into the recruitment process, including designating specific staff members to build and maintain CBO partnerships. In addition, HDCs are trained to identify new partnerships when they are traveling for recruitment trips:

For example, when I was in Miami traveling, I met with a potential organization...and they explain to me what they're doing, I get a sense that this is something that feels legit,

and when I get back, I'll report to my boss, 'hey look I met with [CBO], they seem like the real deal, they really do a lot of great work. I think it's good that we have a

partnership with them.' At that point, my boss will simply...send them a form. And that's kind of how easy the process is. So I'd say there's dozens, at least dozens of organizations that do stuff like that that we work with (Sage College, HDC AO).

At the HDCs, CBO partnerships are a highly valued recruitment tool. On the other hand, LDCs did not have as structured of a system for building CBO partnerships, and they seemed to handle this on an ad hoc basis. For example, when asked about CBOs, one LDC described offering high school students affiliated with a local CBO local partnership something that 'might not look like a traditional Brooks visit, but maybe [we give them] a presentation on the college process' (Brooks, LDC AO). This suggests a group of LIFGWC students visiting Brooks with their CBO is abnormal, and that a more typical or traditional prospective student at Brooks is a student who has the financial resources to visit campus on their own.

Fly-in programs, designed to provide fully paid campus visit opportunities, were used by HDCs to promote college access for LIFGWC students, while LDC campuses used them as a tool to sell their specific campus. The HDCs described fly-in programs as a way for low-income students who may not normally be able to visit a selective college to experience one. For example, the Sage College (HDC) AO explained:

They don't have to state that they intend to apply to Sage, or come to Sage. So really someone with no interest in Sage College can apply [to the fly-in program]...we pay for all of their expenses so that students who normally would not have the opportunity, per se, to really travel and visit a college, will now have someone else who pays for...it without it being a financial burden.

In contrast, LDC AOs describe their fly-in program solely as a competitive recruitment tool to convince underrepresented students to choose their specific campus:

Getting students to campus is a huge priority for us...A lot of small liberal arts colleges look very much the same...I can use all the fancy words that I can during the high school visit, but if they don't actually experience [the college] in-person, then it's not really going to bring them here necessarily (Chase, LDC AO). 
Although offering fly-in campus visit opportunities undoubtedly improves LIFGWC students' college access by providing opportunities to experience campus life and interact with students and faculty, these data reveal that they are all not the same. For HDCs, these programs are more than a recruitment tool, but rather part of a larger set of practices that promote equity.

\section{Reducing Application Barriers}

In addition to using best practice recruitment strategies, selective college AOs aim to improve campus class diversity by addressing three common application barriers: application costs, standardized test requirements, and financial aid. The HDCs used a more holistic approach to reviewing applications that de-emphasizes standardized test scores, including reviewing applications without them:

Coming to mind are lots of examples of individual people who have told us their story, and the numbers suggest it might hurt us to have admitted them, and some people even wonder... 'hey why did you take this kid with this SAT or this ACT?' But we can show them the story, and the case need not be discussed further, because we do a good job of listening to student stories (Robertson HDC).

By placing less emphasis on standardized test scores despite how it might impact their selectivity, the HDCs demonstrate a philosophy that prioritizes LIFGWC students over their own benefit.

LDCs, however, voiced concern about how doing so might hurt their selectivity ranking, and therefore continued to prioritize test scores in evaluating applications. The LDCs either did not make it clear they were aware of how standardized tests disadvantage LIFGWC students, or seemed to largely disregard this. The Tucker (LDC) AO described the challenges they face in admitting LIFGWC students with lower test scores:

We are charged with meeting certain numbers in terms of our average testing, and so at some point, we sometimes will have to be considering more people who have higher testing, and that is predominantly students with more means.

The LDC AOs often felt it was unfortunate that standardized tests disadvantage LIFGWC students, but their sentiment was that this is out of their control and a fault within the larger system. Rankings were a top priority for these campuses, and they viewed admitting students with higher test scores as one way to do this.

HDCs and LDCs also approach fee waivers and financial aid differently. While both types of campuses offer LIFGWC students an application fee waiver, the HDCs make the process easier by having a 'no questions asked' approach. This relieves students of the complicated process of demonstrating waiver qualification. Both HDCs and LDCs meet $100 \%$ of students' financial need, but HDCs are need-blind, meaning they do not consider an applicant's ability to pay tuition when reading their application, while the LDCs are need-aware, meaning they do consider an applicant's ability to pay. The HDCs AOs explained that their generous financial aid policies are central to their access approach, allowing them to be 'hospitable to low-income students,' (Robertson AO) and 'one of the most accessible colleges in the 
country for students from very low-income backgrounds' (Sage AO). Moreover, they are able to offer noloan packages to students who are Pell Grant ${ }^{4}$ eligible.

The LDCs, in contrast, are more constrained by cost, and many times LIFGWC students are pushed out of the selection process due to their high levels of need. For example, the Tucker University (LDC) AO states,

Unfortunately, a lot of selective colleges become very need-aware when they go to things like their waitlist. We have a budget, and we exhaust it to a certain point. Sometimes we get to a point in our admissions process where we've made as many blind decisions as we can, but then we hear from financial services that if you're looking at all these admits, we're over our budget...So you might need to take some students out, or just start considering only the students who can pay full pay.

The AO at Brooks University (LDC) also discusses how LIFGWC students are disadvantaged when their admission decision is a close call, or when it goes to the 'committee room,'

I think the students who are excelling academically and really contributing to their community, if they're really strong they're going to get in. I think sometimes when it's a committee conversation, we just have to be careful, we have to watch our resources and sort of look at those numbers in terms of budget.

LIFGWC students whose applications are on the borderline for admission are severely disadvantaged in the admission process. Again, we find that the differences in these strategies connect to the colleges' diversity philosophies and hold implications for their ability to enroll LIFGWC students.

\section{Discussion and Conclusion}

This study aimed to expand our understanding of why so few high-achieving, LIFGWC students attend selective colleges. While we know that attending selective colleges increases degree completion, future wages, and college affordability for this underrepresented student population (Cohodes \& Goodman, 2014; Andrews et al., 2016), there has been very little increase in the number of students who attend these institutions (Aisch et al., 2017; Hurst, 2019). In fact, a majority of low-income, high-achieving students apply to zero selective schools (Hoxby \& Avery, 2013; Smith et al., 2013). We addressed this larger puzzle by taking a closer look at how selective college admissions offices approached the recruitment of LIFGWC students. Specifically, we compared the approaches used by campuses with relatively high class diversity (HDCs) with those that were less successful (LDCs).

We find that recruitment strategies fall short if they are not backed by a strong institutional mission and commitment to equity and diversity. While both HDCs and LDCs described using similar approaches, they differed in both their guiding philosophy and implementation. Overall, AOs from HDCs were more intentional in actively implementing strategies to make the admissions process more equitable and inviting for lower-income students compared to those from LDCs, and their strategies were linked with a larger mission to improve equity. LDCs lacked both intentionality and mission. Their focus was primarily on improving institutional standing and competing for students, and overall, they were less successful in attracting students from underrepresented class backgrounds to campus.

\footnotetext{
${ }^{4}$ Students whose total family income is $\$ 50,000$ a year or less qualify for the Pell Grant
} 
The differences in philosophy and motivation were evident in how LDCs and HDCs implement their recruiting strategies. LDCs conducted high school recruitment visits at schools where they historically received many applicants from, while HDCs carefully selected high schools with large populations of low-income students for visits. LDCs described fly-in programs-where colleges pay for prospective students' trips to visit their campus-as a way to sell students on their school, whereas HDCs presented it as a way for students to experience a college campus who might not otherwise be able to. LDCs also placed less emphasis on their relationships with CBOs and diversifying their admissions staff than HDCs.

The two campus types also had differing approaches to standardized test scores and financial aid in the application process. HDCs prioritized a more holistic approach to applications and gave less weight to standardized test scores than LDCs. They also aimed to reduce the complexity of the application process, including a no-questions-asked approach to fee waivers. Finally, financial need played much less of a role in the admissions process at HDCs than LDCs, and they leveraged need-blind and no-loan strategies to attract the most talented students, regardless of class position.

Consistent with Rubin's (2011) research on Amherst college, this research highlights the importance of institutional commitment to diversity. We expand upon this work by using a comparative approach to show how equity and diversity philosophies are linked to recruitment policies and success. Campuses guided by deep commitments to equity have more comprehensive and successful approaches to improving college access for LIFGWC students than those who are motivated by improving campus rankings. In line with Golden (2006), Cashin (2014), and Okechukwu (2019), we find that LDCs recruitment practices were in some ways performative or what Cashin calls 'optical' equity efforts. Although they claimed to use many of the same recruitment strategies as HDCs, they implemented them in ways that often prioritized their bottom-line over LIFGWC students. These more surface-level commitments to expanding recruitment were limited in their success. Moreover, LDCs seemed to have fewer resources to devote to financial aid and recruitment, highlighting another potential barrier.

Our findings show that motivating philosophies are critical because they guide institutional priorities, investments, and strategies. It is important to highlight that this study is limited by the small size of the sample and its focus solely on selective campuses. Future research should consider how these processes play out on other types of campuses and in diversity and equity practices beyond admissions. This work also has substantial implications for how campuses recruit diverse talent, and future work should investigate the guiding philosophies and strategies campuses use to recruit other under-represented groups and how these work to promote equity or reproduce privilege.

\section{Author Bios}

Hannah C. Gunther works as a College Access and Persistence Counselor at a high school in New York, NY. She is a 2019 graduate of Colgate University. This research project was a part of her sociology high honors thesis at Colgate.

Janel E. Benson is Associate Professor of Sociology at Colgate University. Her research investigates inequality in the transition to adulthood. She is the co-author of Geographies of Campus Inequality: Mapping the Diverse Experiences of First-Generation Students (Oxford Uni Press, 2020). 


\section{Bibliography}

Ahmed, S. (2012). On Being Included: Racism and Diversity in Institutional Life. Duke University Press Books.

Aisch, G., Buchanan, L., Cox, A., \& Queal, K. (2017, January 18). Some Colleges Have More Students From the Top 1 Percent Than the Bottom 60. Find Yours. The New York Times. https://www.nytimes.com/interactive/2017/01/18/upshot/some-colleges-have-more-studentsfrom-the-top-1-percent-than-the-bottom-60.html?mcubz=1\&_r=0.

Alon, S. (2009). The Evolution of Class Inequality in Higher Education. American Sociological Review, 74(5), 731-755. https://doi.org/10.1177/000312240907400503

Andrews, R. J., Imberman, S. A., \& Lovenheim, M. F. (2020). Recruiting and supporting lowincome, high-achieving students at flagship universities. Economics of Education Review, 74, 101923. https://doi.org/10.1016/j.econedurev.2019.101923

Benson, J. E., \& Lee, E. M. (2020). Geographies of Campus Inequality: Mapping the Diverse Experiences of First-Generation Students. Oxford University Press.

Bowen, W. G., Chingos, M., \& McPherson, M. S. (2009). Crossing the Finish Line: Completing College at America's Public Universities (The William G. Bowen Book 52). Princeton University Press.

Cashin, S. (2014). Place, Not Race: A New Vision of Opportunity in America. Beacon Press.

Cheadle, J. E. (2008). Educational Investment, Family Context, and Children's Math and Reading Growth from Kindergarten Through the Third Grade. Sociology of Education, 81(1), 1-31. https://doi.org/10.1177/003804070808100101

Chetty, R., Friedman, J., Saez, E., Turner, N., \& Yagan, D. (2017, December). Mobility Report Cards: The Role of Colleges in Intergenerational Mobility. Opportunity Insights. https://opportunityinsights.org/paper/mobilityreportcards/

Cohodes, S. R., \& Goodman, J. S. (2014). Merit Aid, College Quality, and College Completion: Massachusetts' Adams Scholarship as an In-Kind Subsidy. American Economic Journal: Applied Economics, 6(4), 251-285. https://doi.org/10.1257/app.6.4.251

Coles, A. (2012). The Role of Community-Based Organizations in the College Access and Success Movement. Institute for Higher Education Policy. Published.

Dache-Gerbino, A. (2018). College desert and oasis: A critical geographic analysis of local college access. Journal of Diversity in Higher Education, 11(2), 97-116. https://doi.org/10.1037/dhe0000050

Dearden, J. A., Li, S., Meyerhoefer, C. D., \& Yang, M. (2017). Demonstrated Interest: Signaling Behavior in College Admissions. Contemporary Economic Policy, 35(4), 630-657. https://doi.org/10.1111/coep.12216

Dynarski, S., Libassi, C., Michelmore, K., \& Owen, S. (2018). Closing the Gap: The Effect of a Targeted, Tuition-Free Promise on College Choices of High-Achieving, Low-Income Students. NBER Working Paper Series. Published. https://doi.org/10.3386/w25349

Engberg, J., Gill, B., Zamarro, G., \& Zimmer, R. (2012). Closing schools in a shrinking district:

Do student outcomes depend on which schools are closed? Journal of Urban Economics, 71(2), 189-203. https://doi.org/10.1016/j.jue.2011.10.001

Glasener, K. M., Martell, C. A., \& Posselt, J. R. (2019). Framing diversity: Examining the place of race in institutional policy and practice post-affirmative action. Journal of Diversity in Higher Education, 12(1), 3-16. https://doi.org/10.1037/dhe0000086

Golden, D. (2006). The Price of Admission: How America's Ruling Class Buys Its Way into Elite Colleges - and Who Gets Left Outside the Gates. Crown. 
Grodsky, E., \& Riegle-Crumb, C. (2010). Those Who Choose and Those Who Don't: Social Background and College Orientation. The ANNALS of the American Academy of Political and Social Science, 627(1), 14-35. https://doi.org/10.1177/0002716209348732

Guinier, L. (2015). The Tyranny of the Meritocracy. Amsterdam University Press.

Hamilton, L., Roksa, J., \& Nielsen, K. (2018). Providing a 'Leg Up' : Parental Involvement and Opportunity Hoarding in College. Sociology of Education, 91(2), 111-131. https://doi.org/10.1177/0038040718759557

Harding, D. J. (2007). Cultural Context, Sexual Behavior, and Romantic Relationships in Disadvantaged Neighborhoods. American Sociological Review, 72(3), 341-364. https://doi.org/10.1177/000312240707200302

Harding, R. (2007). Understanding Social Entrepreneurship. Industry and Higher Education, 21(1), 73-84. https://doi.org/10.5367/000000007780222723

Holland, M. M. (2014). Navigating the Road to College: Race and Class Variation in the College Application Process. Sociology Compass, 8(10), 1191-1205. https://doi.org/10.1111/soc4.12203

Holland, M. M. (2019). Divergent Paths to College: Race, Class, and Inequality in High Schools (Critical Issues in American Education) (None ed.). Rutgers University Press.

Holland, M. M. (2020). Framing the Search: How First-Generation Students Evaluate Colleges. The Journal of Higher Education, 91(3), 378-401. https://doi.org/10.1080/00221546.2019.1647582

Holzman, B., Klasik, D., \& Baker, R. (2020). Gaps in the College Application Gauntlet. Research in Higher Education, 61(7), 795-822. https://doi.org/10.1007/s11162-019-09566-8

Hooker, S., \& Brand, B. (2009). Success at Every Step: How 23 Programs Support Youth on the Path to College and Beyond. American Youth Policy Forum. Published.

Hoxby, C., \& Avery, C. (2013). The Missing 'One-Offs': The Hidden Supply of High-Achieving, Low-Income Students. Brookings Papers on Economic Activity, 2013(1), 1-65. https://doi.org/10.1353/eca.2013.0000

Hurst, A. (2019). Amplified Advantage: Going to a Good College in an Era of Inequality. Lexington Books.

Hurst, A. (2019). College Rankings: Creating an Equitable Model of Transformation and Institutional Effectiveness. Journal of Working-Class Studies, 4(1), 79-97.

Jack Kent Cooke Foundation. (2015). Barron's Profile of American Colleges (2015) List. https://www.jkcf.org/wp-content/uploads/2018/06/The_Transfer_Process2015 list_of_selective_colleges.pdf

Lee, E. (2016). Class and Campus Life: Managing and Experiencing Inequality at an Elite College (1st Edition). ILR Press.

Lee, E. M. (2013). Elite Colleges and Socioeconomic Status. Sociology Compass, 7(9), 786-798. https://doi.org/10.1111/soc4.12068

Leslie Killgore. (2009). Merit and Competition in Selective College Admissions. The Review of Higher Education, 32(4), 469-488. https://doi.org/10.1353/rhe.0.0083

McDonough, P. M. (1997). Choosing Colleges: How Social Class and Schools Structure Opportunity. State University of New York Press.

Okechukwu, A. (2019). To Fulfill These Rights: Political Struggle Over Affirmative Action and Open Admissions. Columbia University Press.

Ovink, S., Kalogrides, D., Nanney, M., \& Delaney, P. (2017). College Match and Undermatch: 
Assessing Student Preferences, College Proximity, and Inequality in Post-College Outcomes. Research in Higher Education, 59(5), 553-590. https://doi.org/10.1007/s11162-017-9482-y

Reay, D., David, M., \& Ball, S. (2001). Making a Difference?: Institutional Habituses and Higher Education Choice. Sociological Research Online, 5(4), 14-25. https://doi.org/10.5153/sro.548

Redford, J., \& Hoyer, K. (2017). First-Generation and Continuing-Generation College Students: A Comparison of High School and Postsecondary Experiences. National Center for Education Statistics. Published. https://nces.ed.gov/pubs2018/2018009.pdf

Roderick, M., Coca, V., \& Nagaoka, J. (2011). Potholes on the Road to College. Sociology of Education, 84(3), 178-211. https://doi.org/10.1177/0038040711411280

Rouse, C. E., \& Barrow, L. (2006). U.S. Elementary and Secondary Schools: Equalizing Opportunity or Replicating the Status Quo? The Future of Children, 16(2), 99-123. https://doi.org/10.1353/foc.2006.0018

Rubin, R. B. (2011). Recruiting, Redefining, and Recommitting: The Quest to Increase Socioeconomic Diversity at Amherst College. Equity \& Excellence in Education, 44(4), 512-531. https://doi.org/10.1080/10665684.2011.613299

Salazar, K. G., Jaquette, O., \& Han, C. (2021). Coming Soon to a Neighborhood Near You? OffCampus Recruiting by Public Research Universities. American Educational Research Journal. https://doi.org/10.3102/00028312211001810

Shamsuddin, S. (2016). Berkeley or Bust? Estimating the Causal Effect of College Selectivity on Bachelor's Degree Completion. Research in Higher Education, 57(7), 795-822. https://doi.org/10.1007/s11162-016-9408-0

Simmons, O. S., \& Hewitt, D. T. (2018). Potential on the Periphery: College Access from the Ground Up (None ed.). Rutgers University Press.

Small, M. L. (2004). Villa Victoria: The Transformation of Social Capital in a Boston Barrio (1st ed.). University of Chicago Press.

Smith, J., Pender, M., \& Howell, J. (2013). The full extent of student-college academic undermatch. Economics of Education Review, 32, 247-261. https://doi.org/10.1016/j.econedurev.2012.11.001

Stevens, M. L. (2007). Creating a Class: College Admissions and the Education of Elites. Harvard University Press.

Stulberg, L. M., \& Chen, A. S. (2013). The Origins of Race-conscious Affirmative Action in Undergraduate Admissions. Sociology of Education, 87(1), 36-52. https://doi.org/10.1177/0038040713514063

Swidler, A. (1986). Culture in Action: Symbols and Strategies. American Sociological Review, 51(2), 273. https://doi.org/10.2307/2095521 